\title{
PELATIHAN PENGGUNAAN MEDIA PEMBELAJARAN DENGAN APLIKASI MICROSOFT POWER POINT
}

\author{
Khairul Anwar Hafizd, Rabini Sayyidati, Herpendi, M.Redhy Rizani ${ }^{1)}$ \\ ${ }^{1)}$ Jurusan Teknik Informatika, Politeknik Negeri Tanah Laut \\ J1. A.Yani, Km 6, Ds. Panggung, Kec. Pelaihari, Kab. Tanah Laut, Kalimantan Selatan \\ *Korespondensi penulis, e-mail: rabini.sayyidati@gmail.com
}

\begin{abstract}
Abstrak: Pesatnya perkembangan teknologi dan informasi dewasa ini dapat membantu guru dan peserta didik menyajikan materi presentasi dengan mudah dan menarik. Hal ini bertujuan agar audience dapat fokus mendengarkan dan tidak bosan. Salah satu media presentasi yang paling umum digunakan adalah aplikasi Microsoft Power Point. Meskipun aplikasi ini mudah didapatkan, tetapi masih ada beberapa guru maupun peserta didik yang belum familiar dengan Ms. Power Point. Sasaran dari pelatihan ini adalah guru dan peserta didik Sekolah Menengah Umum (SMU) di sekitar lingkungan Politeknik Negeri Tanah Laut. Hasil dari kegiatan pelatihan ini adalah optimalisasi penggunaan Ms. Power Point untuk presentasi. Setelah mengikuti pelatihan, peserta yang belum pernah menggunakan microsoft power point merasa sangat terbantu dan tertarik untuk terus menggunakannya, sedangkan bagi peserta yang sudah pernah menggunakan aplikasi ini menjadi lebih tau akan kegunaan fitur-fitur lainnya.
\end{abstract}

Kata Kunci: Media Pembelajaran, Aplikasi, Microsoft Power Point

\section{PENDAHULUAN}

Menyajikan materi dalam sebuah presentasi sebaiknya dikemas dengan kreatif agar dapat menarik perhatian dan menghindari kebosanan audience. Pada Sekolah Menengah Umum (SMU) biasanya peserta didik sudah mulai dilatih untuk melakukan presentasi di depan kelas. Selain itu, guru di SMU juga sering menyampaikan materi yang cukup panjang.

Pesatnya perkembangan teknologi dan informasi dewasa ini dapat membantu guru dan peserta didik menyajikan materi presentasinya dengan mudah dan menarik. Media presentasi sendiri ada bermacammacam, salah satunya adalah dengan menggunakan aplikasi Microsoft Power Point (Ms. Power Point).

Ms. Power Point sendiri adalah aplikasi yang paling familiar digunakan oleh masyarakat karena biasanya aplikasi ini merupakan aplikasi bawaan yang ada di Notebook maupun Personal Computer
(PC) bahkan dapat di install di smartphone.

Berdasarkan hal tersebut, penulis membuat Pengabdian kepada Masyarakat "Bakti Mandiri" berupa Pelatihan Media Pembelajaran dengan Aplikasi Microsoft Power Point. Tujuannya adalah mengembangkan dan memaksimalkan penggunaan Ms. Power Point untuk presentasi. Selain itu, penulis bertujuan untuk membantu menurunkan tingkat gagap teknologi sejak dini.

\section{METODE PELAKSANAAN}

Kegiatan pengabdian kepada masyarakat dilaksanakan dengan cara melakukan pelatihan langsung atau workshop di Gedung 2, Ruang $\mathrm{C}++$, Politeknik Negeri Tanah Laut. Materi disesuaikan dengan kemampuan peserta pelatihan. Pelaksanaan kegiatan dibantu oleh mahasiswa, sehingga setiap ada peserta yang kurang memahami materi maka akan dibimbing oleh mahasiswa 
sehingga tidak menghambat materi yang disampaikan oleh tutor.

\section{TINJAUAN PUSTAKA}

A. Media Pembelajaran

Oemar Hamalik dalam Ahmad (2007), mengemukakan bahwa yang dimaksud dengan media pendidikan adalah alat, metode, dan teknik yang digunakan dalam rangka lebih mengefektifkan komunikasi dan interaksi antara guru dan siswa dalam proses pendidikan dan pembelajaran di sekolah.

Menurut Gerlach dan Ely dalam Asyar (2011), media pembelajaran memiliki cakupan yang sangat luas, yaitu termasuk manusia, materi atau kajian yang membangun suatu kondisi yang membuat peserta didik mampu memperoleh pengetahuan, keterampilan atau sikap. Media pembelajaran mencakup semua sumber yang diperlukan untuk melakukan komunikasi dalam pembelajaran, sehingga bentuknya bisa berupa perangkat keras (hardware), seperti komputer, TV, proyektor, dan perangkat lunak (software) yang digunakan pada perangkat keras itu.

\section{B. Aplikasi}

Abdurahman (2014), menyebutkan aplikasi adalah program siap pakai yang dapat digunakan untuk menjalankan perintah-perintah dari pengguna aplikasi tersebut dengan tujuan mendapatkan hasil yang lebih akurat sesuai dengan tujuan pembuatan aplikasi tersebut. Aplikasi mempunyai arti yaitu pemecahan masalah yang menggunakan salah satu teknik pemrosesan data aplikasi yang biasanya berpacu pada sebuah komputansi yang diinginkan atau diharapkan maupun pemrosesan data yang diharapkan.
Menurut Pramana dalam Rohayah (2015), aplikasi adalah satu unit perangkat lunak yang dibuat untuk melayani kebutuhan akan beberapa aktivitas seperti sistem perniagaan, game, pelayanan masyarakat, periklanan dan hampir semua proses kegiatan.

Menurut Wardana dalam Faruq (2015), aplikasi adalah suatu program komputer yang dibuat untuk mengerjakan dan melaksanakan tugas khusus dari pengguna. Aplikasi merupakan rangkaian kegiatan atau perintah yang dieksekusi oleh komputer.

C. Microsoft Power Point

Supriyanto (2017) menulis, Microsoft Power Point merupakan salah satu program aplikasi microsoft office yang berguna untuk membuat presentasi dalam bentuk slide. Aplikasi ini biasanya di gunakan untuk keperluan presentasi, mengajar dan untuk membuat animasi sederhana. Adanya aplikasi powerpoint, bisa menggantikan cara presentasi konvensional yaitu dengan transparansi proyektor atau sering di sebut dengan OHP (Over Head Proyektor). Karena dengan aplikasi power point, membuat presentasi bisa menjadi mudah karena di dukung dengan fitur-fitur yang canggih dan menarik.

Aditia (2017) menyebutkan bahwa fungsi microsoft power point antara lain adalah:

1. Membuat bahan presentasi dalam bentuk slide-slide.

2. Mempermudah dalam mengatur dan mencetak slide.

3. Membuat bahan presentasi dalam bentuk softcopy sehingga bisa diakses melalui perangkat komputer. 
4. Menambahkan gambar, video, animasi dan audio dalam presentasi sehingga presentasi menjadi lebih menarik dan mudah dimengerti.

\section{HASIL KEGIATAN}

Kegiatan pengabdian ini melakukan beberapa tahapan yaitu acara di awali dengan melakukan pembukaan oleh Ketua Jurusan Teknik Informatika Veri Julianto, M.Si dan sambutan dari perwakilan peserta pelatihan. Setelah itu diberikan sosialisasi mengenai jenis-jenis media pembelajaran yang umum digunakan.

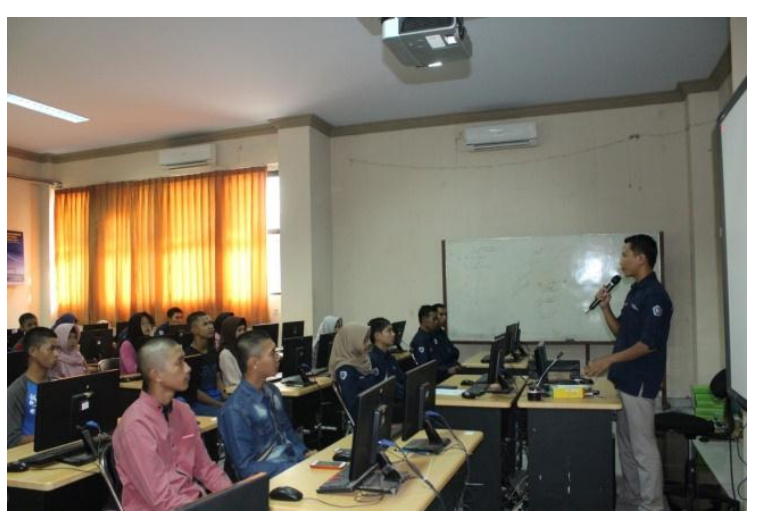

Gambar 1: Pembukaan yang disampaikan oleh Ketua Jurusan Teknik Informatika.

\section{Pelatihan dilaksanakan di Politeknik} Negeri Tanah Laut karena kemudahan dalam mengakses alat dan media. Setiap peserta pelatihan dipinjamkan satu buah laptop beserta tetikusnya. Tutor menjelaskan fungsi-fungsi setiap fitur yang ada di aplikasi power point, sambil mendengarkan peserta dapat praktik langsung membuat presentasi masingmasing. Selain itu, mahasiswa membantu mengajari peserta yang kurang memahami materi sehingga penjelasan dari tutor tidak terhambat. Peserta dipersilakan untuk bertanya dan berdiskusi mengenai hal-hal yang tidak dimengerti maupun jika ada fitur-fitur baru yang ingin mereka coba.

Hasil dari pelaksanaan kegiatan pengabdian kepada masyarakat "bakti mandiri" berupa pelatihan penggunaan media pembelajaran ini adalah peserta menjadi lebih familiar dengan aplikasi microsoft power point. Baik peserta didik maupun guru yang mengikuti pelatihan sangat antusias. Setelah mengikuti pelatihan, peserta yang belum pernah menggunakan microsoft power point merasa sangat terbantu dan tertarik untuk terus menggunakannya, sedangkan bagi peserta yang sudah pernah menggunakan aplikasi ini menjadi lebih tau akan kegunaan fitur-fitur lainnya.

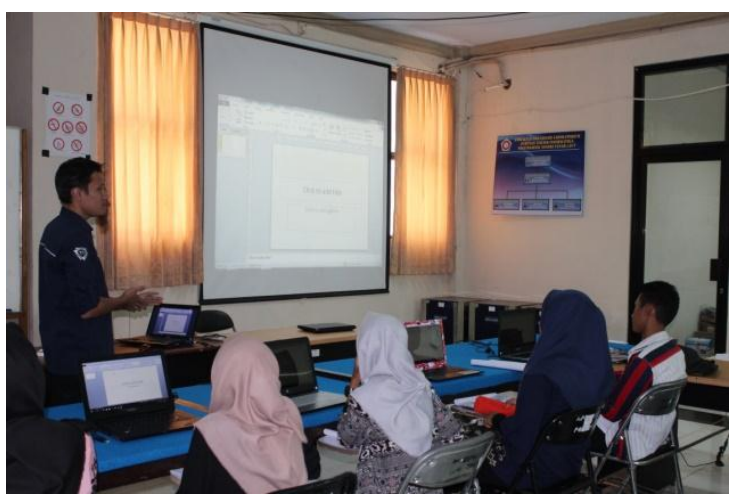

Gambar 2: Tutor memberikan pelatihan kepada peserta yang langsung praktik.

Setelah materi yang disampaikan oleh tutor selesai, kami melihat materi presentasi yang mereka sajikan di microsoft power point terlihat lebih detail 
dan menarik. Tentunya hal ini sangat membantu bagi peserta didik yang nantinya diberi tugas untuk presentasi oleh gurunya di sekolah. Guru-guru yang ikut pelatihan juga dapat menerangkan materi pelajaran di sekolah dengan lebih menarik dan mengurangi rasa kebosanan peserta didiknya.

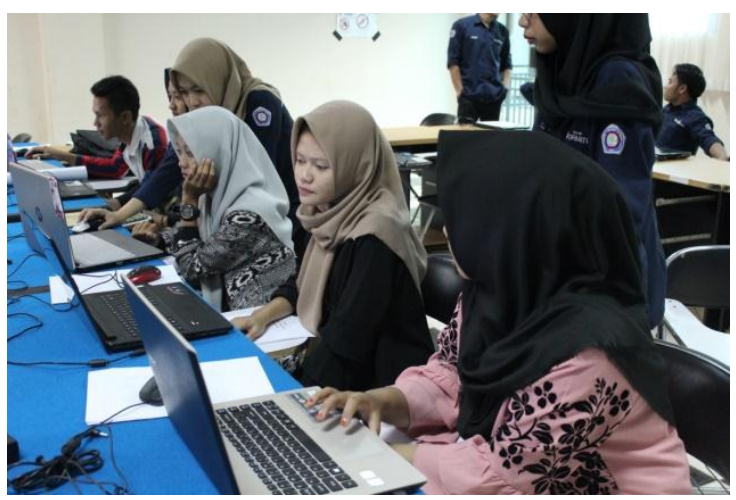

Gambar 3: Peserta dibantu oleh mahasiswa membuat presentasi dengan Ms. Power Point.

Pada akhir pelatihan, peserta dipersilakan untuk bertanya jika masih ada yang belum dipahami. Ternyata hanya sedikit peserta yang bertanya, setelah dievaluasi mereka sudah sangat memahami materi yang telah disampaikan.

\section{KESIMPULAN}

Kegiatan pengabdian kepada masyarakat "bakti mandiri" berupa pelatihan penggunaan media pembelajaran yang diadakan oleh Jurusan Teknik Informatika di Politeknik Negeri Tanah Laut telah sukses dilaksanakan. Pelatihan ini membantu peserta meningkatkan pengetahuan dan kemampuannya dalam membuat presentasi menggunakan microsoft power point.

Berdasarkan masukan dari peserta pelatihan, kegiatan ini diharapkan berlangsung secara kontinyu dengan materi yang juga saling berhubungan sehingga dapat terus membantu meningkatkan sumberdaya manusia khususnya guru dan siswa Sekolah Menengah Umum (SMU) di lingkungan sekitar Politeknik Negeri Tanah Laut.

\section{DAFTAR PUSTAKA}

Abdul Karim, Ahmad. 2007. Media Pembelajaran. Badan Penerbit Universitas Negeri Makasar: Makassar.

Abdurahman, H \& Riswaya, A.R., 2014. Aplikasi Pinjaman Pembayaran Secara Kredit Pada Bank Yudha Bhakti. Jurnal Computech \& Bisnis, Volume 8.

Asyhar, Rayandra. 2011. Kreatif Mengembangkan Media Pembelajaran. Gramedia Pustaka Press: Jakarta.

Faruq, U.A., 2015. Rancang Bangun Aplikasi Rekam Medis Poliklinik Universitas Trilogi. Jurnal Informatika, Volume 9.

Rohayah, S. Sasmito. G.W \& Soemantri,O. 2015. Aplikasi Steganografi untuk Penyisipan Pesan. Jurnal Informatika, Volume 9.

http://ww w.supriet.info/2017/02/fungsidan-manfaat-microsoft-powerpoint.html (diakses pada 11 September 2017) ttp://www.gudangilmukomputer.com/2017 /04/pengertian-dan-fungsi-microsoftpowerpoint.html (diakses pada 11 September 2017) 